\title{
A trajetória do General João Nunes da Silva Tavares (Joca Tavares) durante a Revolução Rederalista de 1893-1895 através de suas cartas e telegramas
}

\author{
The trajectory of General João Nunes da Silva Tavares (Joca Tavares) through \\ biographical data during the federalist revolution of 1893-1895
}

\author{
Gustavo Figueira Andrade ${ }^{1}$ \\ Maria Medianeira Padoin ${ }^{2}$
}

\section{Resumo}

Este trabalho apresenta os resultados de nossa Dissertação de Mestrado em História na Universidade Federal de Santa Maria, utilizando-se da análise de correspondências pessoais do General João Nunes da Silva Tavares (Joca Tavares). Tem por objetivo compreender como sua atuação política e militar durante a segunda metade do século XIX, vinculada a um espaço de fronteira, foi fundamental para articulação de suas relações de poder utilizadas durante a Revolução Federalista de 1893, demostrando o quanto estas estavam ligadas ao espaço fronteiriço platino, capazes de influir nos rumos que assumiu o conflito, e, assim, ampliar as discussões acerca deste conflito para além das fronteiras nacionais. Importante destacar que este estudo faz referência às investigações realizadas durante o Mestrado, financiadas pela CAPES/DS e desenvolvidas pelo autor na Linha de Pesquisa "Fronteira, Política e Sociedade" do Programa de Pós-Graduação em História da Universidade Federal de Santa Maria (UFSM).

Palavras-chaves: Joca Tavares; Biografias; História Política, Revolução Federalista de 1893, Relações de Poder.

\begin{abstract}
This study presents the results of our Master's dissertation in History at the Federal University of Santa Maria, using the analysis of personal correspondence of General João Nunes da Silva Tavares (Joca Tavares), aims to understand how his political and military performance during The second half of the nineteenth century, linked to a frontier space, were fundamental for the articulation of their power relations used during the Federalist Revolution of 1893, demonstrating how they were linked to the platinum border space, capable of influencing the directions assumed by the and thus broaden discussions about this conflict beyond national borders. It is important to highlight that this study refers to

\footnotetext{
1 Graduado em História pela Universidade Federal de Pelotas (UFPEL) e mestre em História pela Universidade Federal de Santa Maria (UFSM). E-mail: figueirandrade@gmail.com

${ }^{2}$ Doutora em História pela Universidade Federal do Rio Grande do Sul; Orientadora do Programa de Pós Graduação da Universidade Federal de Santa Maria (UFSM) e Professora Associada 4 do Departamento de História Co-coordenadora do Comitê História, Regiões e Fronteiras da AUGM. E-mail: mmpadoin@gmail.com
} 
the researches carried out during the Masters, funded by CAPES / DS and developed by the author in the "Frontier, Politics and Society" Research Line of the Graduate Program in History of the Federal University of Santa Maria (UFSM).

Keywords: Joca Tavares; Biographies; Political History; Federalist Revolution of 1893, Power Relations.

\section{Introdução}

A inspiração para traçar as linhas deste artigo partiram das pesquisas desenvolvidas no decorrer de nosso Mestrado em História, durante o qual nos utilizamos das cartas e telegramas ${ }^{3}$ pessoais do General João Nunes da Silva Tavares (Joca Tavares $)^{4}$, as quais deram origem a nossa dissertação, e a partir da qual procuramos apresentar alguns de seus resultados.

Os estudos no âmbito da História Política têm focado sua atuação dos indivíduos e também influenciados por uma ampliação do entendimento do político (ROSANVALLON, 1995), influenciando o desenvolvimento de estudos que procuram compreender "não mais apenas política em seu sentido tradicional, mas, em nível das representações sociais e coletivas, os imaginários sociais, a memória ou memórias coletivas, as mentalidades, bem como as diversas práticas discursivas associadas ao poder" (FALCON, 1997, p. 76).

A historiografia acadêmica que trata da atuação de Joca no período pósProclamação da República e Revolução Federalista destacou sua atuação em momentos distintos, generalizou as informações sobre ele e seu grupo social, demonstrando a necessidade de estudos específicos sobre este personagem, deixando várias lacunas, geralmente o apresentando como um caudilho liberal da região da Campanha Sul-Riograndense.

Tal carência de estudos específicos no âmbito acadêmico acerca deste personagem, possivelmente esteja atrelada ao fato de muitas das fontes sobre as lideranças federalistas da região da Campanha Sul-Rio-grandense estarem guardadas em arquivos privados das famílias, a algumas sendo permitidas o acesso, como foi o caso das pertencentes ao General Joca Tavares. Por outro lado, acreditamos, a marginalização

\footnotetext{
${ }^{3} \mathrm{O}$ critério de seleção da documentação utilizada foi o de privilegiar as que possibilitariam uma melhor análise dos diversos aspectos da vida do sujeito durante a Revolução Federalista de 1893-1895.

${ }^{4}$ ANDRADE, Gustavo Figueira. A Trajetória Política do General João Nunes da Silva Tavares (Joca Tavares): Família, Comunicação e Fronteira. Dissertação (Mestrado em História) - Universidade Federal de Santa Maria, Santa Maria, 2017.
} 
deste personagem e sua família Silva Tavares devem-se ao fato de estarem entre uma história dos vencidos, principalmente por esta família ter estado em lados opostos aos vencedores durante os principais eventos do final do século XIX.

Isso pode ser observado em diversos momentos da história do Rio Grande do Sul, como, por exemplo, na Revolução Farroupilha Joca Tavares e sua família permaneceram e lutaram ao lado dos imperiais e, durante todo a segunda metade do século XIX, esta família pertenceu ao Partido Conservador. Tal situação foi agravada após a Revolução Federalista, conflito que foi vencido pelas forças do governador do Rio Grande do Sul, Júlio de Castilhos.

Assim como a historiografia que prevaleceu no Rio Grande do Sul após a Farroupilha foi a versão que ressaltou o heroísmo farrapo, associada aos liberais Riograndenses, relegando a um segundo plano a atuação dos Silva Tavares, após o término da Revolução Federalista, a historiografia que predominou por muito tempo foi a que privilegiava uma visão enaltecedora de Júlio de Castilhos e do Partido Republicano RioGrandense. Esta procurava esquecer esta guerra civil que havia durado cerca de "31 meses e produziu de dez a doze mil baixas numa população de um milhão de pessoas" (LOVE, 2006, p.110). Um dos motivos era o de que este conflito maculava a história que procurava-se escrever, indo de encontro a uma identidade nacional que se objetivava construir, passando a atribuir a responsabilidade por tal violência aos federalistas e aos estrangeiros que lutavam ao seu lado.

Atualmente, alguns estudos têm privilegiado a atuação desta família, tais como a Dissertação de Mestrado de Leandro Oliveira (2016), Nas Veredas do Império: guerra, política e mobilidades através da trajetória do Visconde de Serro Alegre (Rio Grande do Sul, c.1790-c.1870) analisa a atuação da família Silva Tavares e o processo de imigração luso-brasileira que povoou a metade sul do Rio Grande do Sul e a atuação desta família até 1870. Por outro lado, Jonas Vargas (2007; 2013), em Entre a Paróquia e a Corte: uma análise da elite política do Rio Grande do Sul (1868-1889) e em sua tese denominada Pelas margens do Atlântico: um estudo sobre elites locais e regionais no Brasil a partir das famílias proprietárias de charqueadas em Pelotas, Rio Grande do Sul (século XIX), permite compreender a participação política da família Silva Tavares e a importância econômica e os aspectos sociais desta família durante a segunda metade do século XIX, principalmente através das trajetórias de Dr. Francisco Tavares e de Joaquim da Silva Tavares. 
Dentre os trabalhos que consideramos referências obrigatórias acerca da Revolução Federalista, estão os trabalhos de Ana Luiza Reckziegel (1999), autora de $A$ diplomacia marginal: vinculações políticas entre o Rio Grande do Sul e Uruguai (18931904), e Marcus Vinicius Costa (2006), em A Revolução Federalista de (1893-1895): o contexto platino, as redes, os discursos e os projetos políticos Liberal-Federalistas, estes autores ressaltam a relevância das redes, das fronteiras e para o caráter internacional que assumiu o conflito. Entretanto, estes trabalhos apresentam a atuação do General Tavares de uma forma ampla e que não dão conta de entender a origem destas redes, o espaço de experiência deste personagem e sua trajetória anterior que o alçaram a uma posição de mando e prestígio entre os federalistas

Para dar conta desta problemática, foram desenvolvidas pesquisa e análises com outro "olhar", tanto sobre a historiografia como sobre as fontes, além de trazer novas fontes documentais, através da qual procuramos compreender como o chefe militar João Nunes da Silva Tavares construiu sua trajetória política e suas relações de poder a partir das suas relações pessoais (familiar, política e militar) no período de 1892-1895, a partir das correspondências trocadas com chefes federalistas e legalistas no espaço fronteiriço entre Brasil e Uruguai. Na sequência dos estudos que vêm sendo desenvolvidos pelo autor, procura-se apresentar neste trabalho alguns dos resultados alcançados e também apresentar novas fontes.

Nesse sentido, a partir das correspondências pessoais de João Nunes da Silva Tavares, objetiva-se compreender como foi construída sua trajetória militar e política anterior à Revolução Federalista, dando nova dimensão à extensão de suas redes de relações sociais, como elementos que tornem possível entender a origem do poder e do prestígio do General Tavares que o conduziram a assumir uma posição de liderança entre os federalistas, proporcionando um olhar acerca da atuação e articulação de grupos políticos locais na fronteira meridional do Brasil nos primeiros anos da República.

\section{General João Nunes da Silva Tavares na historiografia}

Dentre os trabalhos clássicos que abordam a atuação do General Tavares, a atuação deste personagem desponta no período que compreende a Proclamação da República e a Revolução Federalista, destaca-se seu envolvimento nestes eventos enquanto uma liderança da região campanha Sul Rio-Grandense, erroneamente associada ao antigo Partido Liberal, pois este havia aderido, juntamente a outros familiares, ao Partido Republicano ainda em julho de 1889. Entrementes, que elementos permitiram 
Joca Tavares ter sido um dos principais nomes envolvidos na articulação de uma oposição a Júlio de Castilhos no período entre a Proclamação e a Revolução Federalista, a ponto de ser homem de confiança do Presidente Deodoro da Fonseca para manter a ordem e a adesão ao novo regime no Rio Grande do Sul e permitido alçar uma posição de proeminência como General Comandante em Chefe das Exército Libertador durante a Revolução?

No sentido de superar essas limitações e compreender sua atuação para além da atuação militar, entendendo-o enquanto político com grande prestígio e poder, é necessário considerar a construção de um espaço de experiência por este personagem ao longo do século XIX. Tal abordagem permite entender sua atuação e influência política, a expertise militar, as redes de relações e as decisões e estratégias adotadas durante esta guerra civil (ANDRADE, 2017), enquanto parte do conturbado processo de consolidação da República no Brasil.

Para entender esse espaço de experiência construído pelo indivíduo ao longo do século XIX, tal prestígio decorria de sua trajetória desde o período imperial, na cidade de Bagé, na qual ele e sua família possuíam diversas propriedades rurais, inclusive na República Oriental do Uruguai, o que lhe conferia poder econômico e prestígio social.

No que diz respeito à sua trajetória militar, diferente de outros eminentes comandantes militares rio-grandenses que haviam aderido aos Farroupilhas, ainda que parente de Bento Gonçalves da Silva, havia construído sua trajetória fiel ao Império. Em 1835, lutou ao lado de seu pai, João da Silva Tavares - posteriormente agraciado com o título de Visconde do Serro Alegre - ao lado das forças imperiais durante a Revolução Farroupilha (1835-1845). Além disso, participou da Campanha contra Oribe e Rosas (1851-1852), lutando nas forças de Manoel Luís Osório, também seu parente, e do Uruguai, em 1864.

O prestígio e o reconhecimento construídos por este personagem devem, em grande parte, ter reunido e organizado um corpo de cavalaria para a Guerra do Paraguai com auxílio de seu irmão José Facundo da Silva Tavares e com o financiamento de seu irmão Joaquim da Silva Tavares, um dos mais ricos charqueadores de Pelotas (PEREIRA, 1901). Durante esta guerra, subordinado ao Visconde de Pelotas, foi o comandante do piquete que capturou e matou Francisco Solano López, em Aquidabã, na fase final deste conflito, conhecida como Campanha das Cordilheiras (PORTO ALEGRE, 1917, p. 82), vindo a receber, em outubro de 1870, do Imperador Dom Pedro II, diversas honrarias, 
dentre elas o título de Barão de Itaqui, de Oficial da Ordem Imperial do Cruzeiro, sendo nomeado Brigadeiro Honorário do Exército Brasileiro.

De regresso do Paraguai, passou a exercer diversas atividades; no âmbito econômico, era possuidor de propriedades rurais no Brasil e no Uruguai que lhe conferiam grande poder econômico e prestígio social, voltou a dedicar-se à pecuária e charqueadora (ANDRADE, 2017). No âmbito político em militar, após a morte de seu pai, assumiu a liderança local do Partido Conservador em Bagé, foi por diversas vezes Comandante Superior da Guarda Nacional nessa cidade (CARVALHO, 2011, p. 123), como também Comandante Militar da Fronteira que abrangia o espaço geográfico entre as cidades de Bagé e Santana do Livramento. Tal vivência em um espaço de fronteira permitiu que estabelecesse uma série de relações que se estendiam inclusive pelo Uruguai, como pode ser observada em carta enviada de Montevidéu pelo General Máximo Santos, Presidente da República do Uruguai, datada de 16 de novembro 1885, na qual escreve [...] Distinguido General y amigo: aprovechando la ida à esa de nuestro amigo el coronel Muniz, le pido tenga bondade de hacerle una visita y saludarle em mi nombre [...] (Acervo Particular da Família Tavares, Cidade de Bagé, RS. Transcrição realizada por Gustavo Figueira Andrade, 2019).

Esta correspondência permite compreender a complexidade da articulação deste personagem na fronteira e o prestígio que pode ter sido mote de sua escolha enquanto comandante da fronteira, pois, além da questão militar, envolvia também uma atuação política neste espaço e que fosse reconhecida dos dois lados da fronteira, legitimando sua autoridade. Por outro lado, permite um olhar sobre a origem e a amplitude das relações deste personagem que apoiaram as forças federalistas a partir do Uruguai durante a Revolução Federalista, eram relações que provinham, desde muito antes, do conflito e que seriam ativadas nos momentos chaves.

Alinhado com as discussões e os problemas que grassavam no âmbito nacional, entre 1885 e 1886, foi um dos principais nomes do movimento abolicionista na cidade de Bagé, que declarou a abolição em 1884.

No âmbito político provincial, seguindo os passos políticos de seu pai, Joca veio a ser nomeado por D. Pedro II o terceiro Vice-Presidente da Província do Rio Grande do Sul, em agosto de 1885. Quanto a seus irmãos, suas trajetórias evidenciam que o poder desta família abrangia desde a esfera local até a nacional, como, por exemplo, José Bonifácio da Silva Tavares foi vereador diversas vezes e presidente da Câmara Municipal de Bagé; já Francisco da Silva Tavares, havia se formado em Direito Faculdade de Direito 
do Largo São Francisco, em São Paulo, e chegou a ser Deputado Provincial entre 1871 e 1888 e Geral do Império entre 1886-1889 e governador do Rio Grande do Sul por breves dias em 1890, assim como Joaquim da Silva Tavares, que foi presidente provincial em 1888 e um dos charqueadores mais ricos do final do século XIX (VARGAS, 2014).

Logo após a Proclamação da República, em 1889, por determinação do próprio Presidente da República, Marechal Deodoro da Fonseca, Joca Tavares foi nomeado, novamente, Comandante Militar da Fronteira, de 1890 a 1891 (REIS, 1911, p. 99; 103). A relação de proximidade entre estes personagens decorre também do período da Guerra do Paraguai e, possivelmente, devido ao fato de Deodoro da Fonseca também ter pertencido ao Partido Conservador e ter sido presidente da Província do Rio Grande do Sul, em 1886.

Enquanto no restante do Brasil as elites políticas imperiais haviam mantido a participação na máquina estatal, no Rio Grande do Sul o processo adquiriu peculiaridades que a diferenciavam. Tal peculiaridade estava associada ao processo da Proclamação da República e os contornos políticos determinados pelos projetos de poder em disputa, de um lado, representados pelos interesses políticos do Partido Republicano Rio-Grandense (PRR), liderado por Júlio de Castilhos e composto em grande parte por republicanos históricos e por republicanos adesistas, em sua maioria antigos membros do extinto Partido Conservador. Por outro lado, pelos antigos membros do antigo Partido Liberal, que dominava o cenário político do Rio Grande do Sul nas últimas décadas do Império do Brasil e que tinha por principal liderança o conselheiro Gaspar Silveira Martins.

Durante a Proclamação, Gaspar Silveira Martins, que era chefe do Partido Liberal e presidente da Província do Rio Grande do Sul, partiu para o Rio de Janeiro para o substituir o gabinete Ouro Preto, tentativa frustrada durante o trajeto, durante o qual recebeu a notícia da Proclamação da República (PICCOLO, 1992, p. 65), sendo preso logo após chegar ao Rio de Janeiro e enviado para o exílio na Europa, regressando apenas em 1892 (MORITZ, 2005, p.33-34).

O contingente de republicanos no Rio Grande do Sul, no alvorecer do novo regime, era composto pelos históricos membros do Partido Republicano Rio-grandense $(\mathrm{PRR})^{5}$ e por adesistas, não tão bem vistos pela elite do partido, chefiada por Júlio Prates

\footnotetext{
${ }^{5}$ RODRÍGUEZ, R. V. Castilhismo: uma filosofia da república. Porto Alegre: Escola Superior de Teologia São Lourenço de Brindes; Caxias do Sul: Universidade de Caxias do Sul, 1980. O PRR contava com grupos que se pautavam por uma matriz política de cunho Positivista, a qual veio a ser adaptada por Júlio de Castilhos a realidade do Rio Grande do Sul e adquirindo peculiaridades em relação ao pensamento de August Comte. Este partido também possuía adeptos que seguiam uma vertente liberal como, por exemplo,
} 
de Castilhos. Ainda que bem organizados, o grupo do PRR não contava com o poder que desfrutavam no Rio Grande do Sul os antigos membros do Partido Liberal do Império. Entretanto, constituíram a única opção viável para compor um governo republicano provisório a ser nomeado por Deodoro até as eleições. Cabe ressaltar que o PRR passou a ter suas fileiras fortalecidas antes da Proclamação em 1889, por as principais lideranças conservadoras Sul-rio-grandenses terem se declarado republicanas. Este foi o caso do Dr. Francisco da Silva Tavares, chefe provincial do Partido Conservador, José Bonifácio da Silva Tavares e Joaquim da Silva Tavares, todos irmãos de Joca Tavares, chefe dos conservadores na cidade de Bagé, o qual abdicou seu título nobiliárquico, passando todos, ainda que temporariamente, às fileiras do PRR, atitude que isolou muitos dos antigos membros do Partido Liberal não adesistas.

Nesse sentido, o Presidente da República, Marechal Manoel Deodoro da Fonseca, nomeou Júlio de Castilhos para compor o governo rio-grandense, alvitre que recusou e cedeu lugar a José Antônio Correia da Câmara, segundo Visconde de Pelotas, preferindo Castilhos permanecer como Secretário de Governo (FRANCO, 2012). Neste contexto de disputas típico da cultura política do final do século XIX, o projeto político do PRR passou a realizar as "derrubadas", práticas políticas utilizadas durante o Período Monárquico no Brasil, no qual eram destituídos dos cargos os membros do partido que perdiam as eleições. Castilhos passou, gradualmente, a destituir os antigos liberais e aparelhar o governo com membros do PRR.

A atitude sectária de Castilhos causou dissidência dentro do próprio PRR, como o caso de Demétrio Ribeiro e Barros Cassal, Joaquim de Assis Brasil e os Silva Tavares. Para exercer a oposição, foi organizada a União Nacional em 1890, agremiação política para a qual convergiram políticos, tais como Joca Tavares e a família Silva Tavares, além de outros republicanos dissidentes e outros ex-liberais.

A amizade existente entre Deodoro e Joca Tavares não impediu que este se posicionasse contrariamente ao golpe de Deodoro da Fonseca, em novembro de 1891, pois o General Tavares foi um dos principais nomes envolvidos no levante junto a inúmeras guarnições militares e de forças civis em armas, chegando a ser nomeado comandante em chefe das forças em operação no sul do Rio Grande do Sul. Essas forças organizadas resistiram ao golpe de Deodoro e ao governador Júlio de Castilhos, que havia manifestado apoio ao Presidente da República. Como resultado desses eventos, a figura

Joaquim Francisco de Assis Brasil, o qual veio a fazer oposição a Castilhos e o formato dado ao seu governo, considerado autoritário por este personagem. 
do General Tavares e a de seus irmãos - um dos principais núcleos de oposição - surgem como importante força que poderia resistir a Castilhos através das armas, se fosse preciso.

A situação política decorrente desses eventos alçou ao poder uma junta governativa que ficou caracterizada pela instabilidade e ingovernabilidade, a qual foi alcunhada por Júlio de Castilhos como sendo um "governicho" (FRANCO, 1996). Esta junta governou até que pudessem ser organizadas novas eleições em 1892.

O General Tavares continuava, assim como sua família, na articulação da oposição, potencializada na organização do Partido Federalista, em 1892, na cidade de Bagé, reunindo importantes lideranças dissidentes, antigos líderes conservadores, liberais, comerciantes, charqueadores, personagens que haviam perdido cargos e acesso aos benefícios do Estado com a postura sectarista do PRR. Eram líderes de diversas regiões do Rio Grande do Sul, no entanto, com a defecção da participação de muitos líderes republicanos dissidentes e contrários a um governo Parlamentarista, tais como Joaquim de Assim Brasil, Barros Cassal e Demétrio Ribeiro. Essa reunião pode ser entendida como um claro exemplo das relações de poder de Joca Tavares e de seus irmãos no cenário político do período, conseguindo congregar interesses diversos e antigos inimigos, reunindo-os para pensar em um projeto que seria comum.

Com o regresso de Gaspar Silveira Martins do exílio, também passaram a contar com o apoio deste líder, congregando antigos chefes liberais aos antigos inimigos [liberais] conservadores, em torno de um projeto de governo liberal. Como resultado desta reunião, sairiam o General Tavares como candidato a concorrer ao governo do Rio Grande do Sul, enquanto Gaspar Silveira Martins concorreria à Presidência da República (PESAVENTO, 1983, p. 80).

Tal projeto liberal enfatizava a defesa dos poderes locais e contra a interferência do governo estadual no seu funcionamento, na defesa da preponderância do Poder Legislativo sobre o Executivo, a defesa de um Poder Judiciário estadual nomeado pelos poderes locais, liberdade de imprensa, liberdade e respeito à propriedade e o fim da Constituição de 1891 (FLORES, 1993; MORITZ, 2005; FRANCO, 2012), defendendo os interesses de comerciantes, pecuaristas e charqueadores, dentre outros pequenos possuidores de terras que se identificaram com o projeto federalista. Esse grupo defendia, em sua maioria, o parlamentarismo e um federalismo da seguinte forma: nos estados, uma descentralização entre a capital e os municípios, e, na relação desses para com poder central, uma maior centralização, com menor autonomia dos governos estaduais (ROSSATO; ANDRADE, 2019). Isso remetia ao antigo modo de funcionamento político 
durante o Império do Brasil e quanto ao retorno de uma capacidade destas elites locais acessarem o poder central novamente e fazer representar seus interesses

Por outro lado, representavam a oposição ao governo Castilhista, cujo projeto de governo e de poder previa um Poder Executivo forte em detrimento do Poder Legislativo enfraquecido, reeleição indefinida do chefe do Executivo, excluindo a oposição do processo decisório, um governo autoritário no qual o chefe do Executivo seria um ditador carismático, tendo por forma de governo uma República Presidencialista e federativa com estados fortes (FLORES, 1993), princípios que estavam presentes na Constituição RioGrandense de 1891 e sairia consolidada após a vitória sobre os federalistas em 1895.

Em 1892, antevendo turbulências advindas da ação do PRR e da inevitabilidade do conflito, o governador do Rio Grande do Sul, Visconde de Pelotas, precisaria de um homem que pudesse fazer frente a um levantamento Castilhista, para tanto, nomeava Joca Tavares ao cargo de $1^{\circ}$ Vice-Governador, declarando, através de correspondência, ser “[...] inevitável a guerra civil, como já declarei ao governo central, daí a necessidade de colocar o meu amigo [Joca Tavares] à testa da administração que aqui forçosamente tentarão tirar-me, [...]" (Acervo Particular da Família Tavares, Cidade de Bagé, RS. Transcrição realizada por Gustavo Figueira Andrade).

De fato, o General Tavares, na qualidade de Vice-Governador, assumiu o governo na cidade de Bagé, transferindo para essa cidade a capital do Estado, ao mesmo tempo em que o Júlio de Castilhos assumia, em Porto Alegre, logo transferindo o cargo para Fernando Abbott, ficando o Rio Grande do Sul com dois governos e duas capitais.

$\mathrm{Na}$ tentativa de evitar uma guerra civil que se fazia iminente, Joca Tavares trocou muitas correspondências com o Marechal Floriano Peixoto, procurando resolver a grave situação em que se encontrava o Estado (ANDRADE, 2017), conforme é possível perceber em telegrama no qual declara que

[...] Não mandei emissário algum, menos ordem instituir governo contrário patrióticos princípios revolução triunfante. Fiz regressar oficiais, chamados aqui, por considerá-los republicanos sinceros e ainda porque esforço-me por retirar política das fileiras do Exército. Esta explicação é dada a meu velho camarada, que muito me merece e a quem saúdo afetuosamente. Floriano Peixoto (Acervo Particular da Família Tavares, Cidade de Bagé, RS. Transcrição realizada por Gustavo Figueira Andrade. Grifo nosso).

Através dessas correspondências, podemos perceber as tratativas políticas e a dubiedade das ações de Floriano Peixoto, mas também evidenciam que redes de relações de Joca Tavares se estendiam à capital nacional e a outras partes do Brasil, portanto, 
permitindo entendê-lo como uma liderança para além do nível local e regional. É possível identificar que muito das amizades e contatos no Rio de Janeiro foram criados nos tempos da Guerra do Paraguai, principalmente a partir da forma como o Presidente Floriano Peixoto trata o General Tavares na carta que apresentamos anteriormente, na qual o chamava de "Velho amigo e camarada" (ANDRADE, 2017).

O General Joca Tavares reuniu forças para resistir às forças de Castilhos em Bagé, de onde governava, entretanto, se, em 1891, o General Tavares conseguiu debelar as forças do PRR, os castilhistas também haviam aprendido a lição, articulando-se com o governo do Presidente Floriano Peixoto e com diversos comandantes e oficiais do Exército Brasileiro que estavam aquarteladas no Estado, os quais contavam com diversos adeptos a sua ideologia dentro das fileiras.

A justificativa do Governo Federal era de que os apoiadores do General Tavares, dentre eles Gaspar Silveira Martins, representariam forças monarquistas e ameaças restauradoras. Sem ninguém que pudesse frear os ímpetos de Castilhos, este passaria, futuramente, a ordem a seus correligionários, para que "não poupe adversários: castigue nas pessoas e bens, respeitando a família" (ESCOBAR, 1983, p. 174), pois enfrentariam perseguições políticas aos adversários. Diante da superioridade de meios e numérica que as forças de Castilhos passaram a contar ao serem apoiadas pelas forças do Exército Brasileiro, restava a Joca Tavares e às forças leais a ele renderem-se em Bagé.

Vencida a possibilidade de resistência, muitos federalistas emigraram para o Uruguai e Argentina, segundo Moacyr Flores e Hilda Flores (1999), chegando a um número de dez mil rio-grandenses. Do exílio, os federalistas passaram a organizar forças revolucionárias, até que fosse realizada a invasão do Rio Grande do Sul em fevereiro de 1893.

As forças federalistas invadiam o Rio Grande do Sul, tendo Gaspar Silveira Martins como o chefe político da Revolução, o General Gumercindo Saraiva como líder e Joca Tavares como General Comandante em Chefe do Exército Libertador, ou seja, seria o responsável pela organização e comando das forças federalistas. No entanto, isso não representava que seria um comando centralizado e com a mesma disciplina de forças regulares, de modo que o General Tavares enfrentou muitas desavenças internas entre outros demais chefes federalistas que comandavam pequenas forças que haviam recrutado. As divergências entre interesses pessoais estavam acima de qualquer objetivo maior da Revolução, somados às frequentes dificuldades logísticas e materiais que inviabilizavam obter resultados contundentes (ANDRADE, 2017). 
Joca Tavares estava com 77 anos de idade. Frequentemente, em suas cartas referese ao fato de estar doente (ANDRADE, 2017), desgostoso com as dissenções políticas entre os federalistas. Contando com poucos recursos e financiando a guerra com a venda de seus bens, decidiu retirar-se do comando e foi substituído pelo Almirante Saldanha da Gama, em 1894. Importante destacarmos que Joca Tavares não deixou de comandar e articular as lideranças federalistas em torno da revolução, a ponto do próprio Saldanha da Gama aconselhar-se e, constantemente, pedir opiniões ao General Tavares, pedindo que intermediasse junto a outros chefes federalistas (ANDRADE, 2017). Contrariando o líder político da revolução, Gaspar Silveira Martins, Joca Tavares foi o principal responsável pelas tratativas de pacificação em 1895, período em que seu prestígio e a extensão se suas redes em um âmbito nacional podem ser observados, principalmente por ter sido ele, juntamente com seu irmão Dr. Francisco Tavares, a encetarem as negociações de pacificação do Rio Grande do Sul.

Ao encontro desta atuação e prestígio em nível nacional, apresentamos uma correspondência que foi enviada ao General Tavares, em 1895, pela Câmara Municipal da cidade de Ouro Preto, estado brasileiro de Minas Gerais, referindo-se à pacificação da Revolução Federalista no Rio Grande do Sul que deu origem ao fim ao conflito, conforme poderá ser observado abaixo:

\section{CÂMARA MUNICIPAL DE OURO PRETO}

N. 132

25 de Setembro de 1895.

A Câmara Municipal de Ouro Preto do Estado de Minas Gerais, em seu nome e no de seus municípios, felicita a Vossa Excelência como ilustre chefe do esforço patriótico exército revolucionário e bem assim aos seus dignos companheiros, pela pacificação do glorioso Estado do Rio Grande do Sul, de que é Vossa Excelência um dos mais distintos filhos, e por cuja liberdade tantas vezes Vossa Excelência arriscou a sua preciosa existência. Deus guarde Vossa Excelência. O Vice-Presidente e Agente Executivo, em exercício, Olympio Ferrer de Faria Oliveira, Francisco de Castro de Faria Ribeiro, Agostinho José Carlos [?], João Xavier dos Santos, Lauro de Lima. Carta enviada pela Câmara Municipal de Ouro Preto ao General João Nunes da Silva Tavares. (Acervo Particular da Família Tavares, Cidade de Bagé, RS. Transcrição realizada por Gustavo Figueira Andrade, 2019).

Nesta carta assinada por diversas lideranças políticas mineiras, o parabenizam pela pacificação da guerra civil que assolava o Brasil, muito além de evidenciar seu prestígio e a possibilidade da amplitude de suas redes de relações, também pode ser importante indício da origem do apoio de antigos monarquistas e dos nomes envolvidos no suporte às forças federalistas revolucionárias que operaram no sul do Brasil durante o conflito. Esses episódios não encerraram sua atuação política, o General Joca Tavares 
seguiu atuando na política estadual, vindo a falecer em 1906, na cidade de Bagé. (ANDRADE, 2017).

\section{As correspondências pessoais de Joca Tavares e novos elementos para a compreensão de sua atuação política e militar durante a Revolução Federalista}

A análise de correspondências permitiu que identificássemos uma série de informações que dizem respeito à atuação política e militar deste personagem durante o conflito, especialmente, evidenciando, pela análise de suas relações de poder, a presença de fenômenos sociais do caudilhismo, de relações clientelísticas e a importância das relações familiares na articulação e mobilização de lideranças federalistas. Nesse sentido, muitos chefes militares e políticos federalistas referiam-se a Joca como compadre, velho camarada, velho amigo, evidenciando a existência de uma rede de relações de parentesco e sociais entre os líderes federalistas.

Pela carta enviada da cidade de Pelotas pelo Dr. Francisco da Silva Tavares ao General Tavares, seu irmão, datada de 14 de agosto de 1895, na qual escreve, dizendo: "Compadre Joca, acabo de conferenciar com o General Galvão e Estácio Azambuja (...)" (TAVARES, 2004, p.329).

Em carta enviada da cidade de Porto Alegre, no dia 14 de junho de 1892, pelo Visconde de Pelotas ao General Tavares, tratando da situação política em que se encontrava o Rio Grande do Sul e comunicando-lhe sua decisão de transmitir-lhe o cargo de governador frente à iminência da eclosão da guerra civil, termina por despedir-se, dizendo "Sou com o maior apreço, de Vossa Excelência velho camarada e amigo obrigadíssimo. Visconde de Pelotas (Acervo Particular da Família Tavares, Cidade de Bagé, RS. Transcrição realizada por Gustavo Figueira Andrade).

Em 1895, o federalista Alexandre Collares, em carta enviada da cidade uruguaia de Paysandu, endereçada ao General Tavares, refere-se a este dizendo-lhe: "Sinto imensamente não poder servir o velho amigo com os cavalos que me pede, faz 18 dias que por aqui andou um enviado do Almirante Saldanha, pedindo-nos também recursos de cavalos" (ANDRADE, 2017, p. 148).

Tais relações, ainda que não isentas de dissenções, demonstram o prestígio capitalizado por ele, derivado do reconhecimento por seus pares da experiência adquirida pelo personagem durante o século XIX, principalmente durante a Guerra do Paraguai, ligando-o a uma elite militar e política de abrangência nacional. Tal prestígio e 
conhecimento dos meandros da guerra e da fronteira seriam fundamentais para a condução do conflito.

Por outro lado, ainda no âmbito das relações pessoais, as relações de compadrio eram muito comuns no século XIX. Esse entendimento remete à compreensão de família neste período, a qual vem a ser distinta da concepção que temos no presente. Segundo Richard Graham, existiria um entendimento de que "os limites de uma família iam muito além do pai, da mãe e dos filhos [...] ser padrinho, afilhado, compadre ou comadre no Brasil [...] implicavam obrigações mútuas de ajuda nas eleições ou na garantia de cargos no governo [...] (1997, p.37)", sendo, portanto, uma família extensa que ia além dos laços consanguíneos.

Nesse âmbito das relações pessoais e dos interesses familiares eram escolhidos os chefes mais próximos, com os quais se correspondia com mais frequência e tratava de assuntos de cunho político e decisões a serem tomadas.

Por outro lado, a forte presença de relações pessoais indicam a existência de uma imbrincada relação entre os interesses privados e os interesses pretendidos da revolução, conforme pode ser exemplificado em duas situações. A primeira, diz respeito ao interesse do General Tavares em negociar com o governo legalista a soltura de seu irmão, João Facundo da Silva Tavares, preso pelos castilhistas, em troca de legalistas capturados em combate (ANDRADE, 2017, p. 110). A segunda, se refere ao financiamento do conflito, o qual foi realizado pelos líderes federalistas que haviam empenhado e vendido seus bens pessoais para conseguir crédito e comprar suprimentos. Tal situação é evidenciada através de uma carta enviada pelo General Tavares a Saldanha da Gama, em 7 de maio de 1895, na qual afirma ter comprado cavalos "com alguns poucos recursos que dispunha, e tirei dinheiros a crédito e fiz compras a prazo, para tudo isso conseguir, tenho lutado com enorme dificuldade [...]" (ANDRADE, 2017, p. 111).

As correspondências permitem compreender algumas das formas pelas quais as forças federalistas eram sustentadas durante o conflito. Nesse sentido, além do apoio de antigas forças monarquistas do restante do Brasil e residentes no exterior, principalmente na Europa, existiu em torno do General Tavares, assim como de outros líderes federalistas e seus grupos, redes de apoiadores residentes ou exilados no Uruguai e na Argentina que simpatizavam com a causa federalista, deslindando uma complexa rede de relações que era articulada através do prestigio dos líderes federalistas. Tal mobilização de recursos nacionais e internacionais permite compreender a amplitude das relações de poder desses líderes fronteiriços, a qual pode percebida através da carta enviada pelo Almirante 
Saldanha da Gama a Joca Tavares, ao falar sobre a falta de cavalos para suprir as forças e a necessidade de consegui-los, diz o seguinte: [...] Já apelei para os amigos de Montevidéu. Queira Vossa Excelência fazer o mesmo para os de Cerro Largo e Taquarembó [...]” (ANDRADE, 2017, p. 125).

Estas articulações e constantes pedidos feitos ao General Tavares que provinham de outros líderes federalistas revelam a capacidade de articular e fazer circular bens e informações nela, permite-nos asseverar seu papel de mediador no grupo social federalista. Nosso entendimento do conceito mediador para compreender a atuação do General Tavares durante a revolução parte da perspectiva de Michel Bertrand (1999), José María Imízcoz (2011) e Julio Cezar Rodríguez Treviño (2013), ou seja, o indivíduo que ocupa papel de centralidade em uma rede de relações serve como uma ponte entre grupos e subgrupos, controlando informações, fazendo circular favores, bens ou serviços, de algum modo que lhe proporcione obter vantagens. Nesse sentido, sua atuação enquanto mediador remete mais a seu capital imaterial enquanto indivíduo e à utilização deste em sua rede de relações sócias e não apenas restrita ao âmbito das relações com o Estado.

Por sua vez, tal relação entre Joca Tavares e os constantes pedidos que lhe eram feitos, tais como solicitando informações, ajuda para solucionar problemas, recursos de guerra, para mediar as desavenças entre os líderes, e até mesmo dinheiro, configuram, de acordo com Ângela de Castro Gomes (2000), uma prática de clientelismo.

Essas práticas evidenciam "relações assimétricas de poder, comuns no campo da política, a partir do qual um dos termos - o demandante - dirige-se a um interlocutor, por definição 'poderoso', que por isso mesmo tem a capacidade e muitas vezes o dever de atendê-lo" (GOMES, 2000, p. 32). Por outro lado, o atendimento das demandas que lhes eram postas também colocam o General Tavares numa posição de mediador dentro do grupo federalista e demonstram o reconhecimento da autoridade de quem se pede um favor, como alguém capaz de resolver problemas, conceder favores e fazer circular os serviços necessários, acessar outras círculos de poder aos quais o personagem possui acesso, assim como evidenciam a existência de vínculos de lealdade e solidariedade entre eles. A presença desses aspectos possibilita entender a existência de relações clientelísticas e a sua atuação enquanto um caudilho.

Acerca da práticas clientelísticas, algumas das correspondências que apresentam esses elementos, como, por exemplo, a carta do dia $1^{\circ}$ de novembro de 1893 , através da qual o Cônego João Inácio de Bittencourt e Pedro Rodrigues de Borba, ao escreverem da cidade de Bagé ao General Tavares, na qual passam informações acerca de um indivíduo 
que foi acusado por tentar envenená-lo, e ao término da carta, colocam-se sob sua proteção: “[...] Garantimos que tendo pleno conhecimento desse moço que veio somente ajudar a defender a nossa causa. Saudamos a Vossa Excelência e sentimos grande prazer em estarmos debaixo da vossa proteção. [...]" (ANDRADE, 2017, p. 80. Grifo nosso).

Esta prática clientelística por esses personagens durante o conflito pode ser entendida como parte de seu espaço de experiência e da cultura política do período, principalmente pelo fato de que muitos dos líderes federalistas que comandaram forças do Exército Libertador durante a Revolução compuseram as fileiras da Guarda Nacional durante o período imperial.

Acerca da existência de práticas clientelísticas na Guarda Nacional, André Fértig (2010) destaca que, muito mais do permitir o recrutamento de homens, era um dos principais meios utilizados para finalidades clientelistas, pois estes coronéis tinham, sob sua jurisdição de comando, as tropas da Guarda Nacional de outras cidades, que lhes possibilitavam realizar a "cooptação de homens que poderiam ser seus clientes" (FÉRTIG, 2010, p. 106) e, caso necessário, mobilizá-la em prol de seus interesses políticos ou militares, como de fato ocorreu em 1893-1895 durante a contenda. No caso do General Joca Tavares, o fato de ele ter pertencido a esta instituição, reunido um corpo de 500 homens para lutar na Guerra do Paraguai e sido Comandante Superior da Guarda Nacional de Bagé por mais de 5 vezes entre 1871 e 1891, evidenciam uma atuação de seu prestigio e permitiu construir uma trajetória política e também expertise em reunir soldados que foi utilizada durante a Revolução Federalista (ANDRADE, 2017).

Essa situação se evidencia diante de uma análise quantitativa e qualitativa das correspondências. A quantificação do volume delas torna possível entender que apenas recebiam muitas cartas os indivíduos reconhecidos pelo remetente como portadores da capacidade de conceder benefícios, solucionar problemas, atender solicitações. A qualitativa, por sua vez, permite observar que, na relação de confiança que envolve o receber, ler e responder correspondências, muitos dos líderes negociavam com outros chefes federalistas, enquanto estes, por sua vez, comunicavam-se, fazendo pedidos, solicitavam-lhe informações, pediam soluções aos seus problemas, recursos de guerra, para mediar as desavenças entre os líderes, e até mesmo dinheiro, configurando, de acordo com Ângela de Castro Gomes (2000), uma prática de clientelismo.

No que se refere ao caudilhismo como uma categoria de análise da atuação do General Tavares, sua posição de mediação dentro do grupo federalista envolvendo práticas clientelísticas, revela os mecanismos que envolviam a capacidade arregimentar 
homens, reunir as forças militares e mantê-las em combate. Acerca da atuação dos caudilhos, Valentina Ayrolo (2012) assevera que estes personagens eram conhecidos por serem especialistas em redes, chefes militares de grande carisma com apoio popular e ligados por fortes laços de lealdade com seus subordinados. Eles eram indivíduos que possuíam grande influência em suas localidades e, "utilizando suas redes de relações pessoais, trataram de erguer um sistema de alianças como base de uma ordem política estável" (DONGHI, 1965, p. 33). A atuação desses caudilhos também relaciona-se à existência de um sistema que tinha por base a lealdade pessoal, criava, assim, inúmeras maneiras de dependência entre patrão e clientes, numa troca mútua, tanto com setores subalternos quanto com indivíduos economicamente superiores a ele, transformando-o em cliente e direcionando-o em prol de seus objetivos (SAFFORD, 1991, p. 63). Por fim, Carlos Real de Azúa irá destacar que ,sem o exercício distributivo, “o prestígio dos caudilhos não alcançaria grandes proporções" (AZÚA, 1969, p. 124).

A existência de tais relações entre os comandantes entre si e para com os subordinados, juntamente com a experiência adquirida enquanto chefe político e militar por Joca Tavares durante sua participação nos conflitos do século, explicariam parte de seu prestígio entre os líderes federalistas e quão fundamentais foram para sua escolha como comandante em chefe do Exército Libertador durante o conflito (ANDRADE, 2017). Sua liderança não teria cessado mesmo depois de haver passado o comando em chefe da revolução ao Almirante Luís Felipe Saldanha da Gama, em 1894. Isso decorre do fato de que o almirante não conhecia as táticas da guerra a gaúcha ${ }^{6}$ numa zona de fronteira, amplamente utilizada pelos federalistas devido à desproporcionalidade de meios contra as forças legalistas. Por outro lado, não possuiria total acesso ao complexo mundo das redes de relações entre os líderes federalistas, repleta de peculiaridades, como, por exemplo as diversas desavenças e os interesses que os motivavam, para articulá-las em seu entorno. As correspondências apontam que Joca Tavares conhecia muito bem esse meio e esse terreno, de modo que sua mediação e liderança seguiu sendo consultada e solicitada por diversas vezes até 1895 , quando encetou as negociações de paz que marcaram o término do conflito.

\footnotetext{
${ }^{6}$ Esta forma de fazer a guerra por diversas vezes no Rio Grande do Sul ao longo do século XIX é uma forma de combater também a conhecida como sendo Montonera e praticada no mundo hispano-americano. Dentre suas características, caracteriza-se por movimentos rápidos, geralmente a cavalo, conduzida por indivíduos que eram exímios conhecedores do terreno onde atuavam, onde forças em menor número enfrentam forças mais numerosas e melhor organizadas, no entanto evitando oferecer combate direto, procurando extenuar o moral, os recursos do inimigo ou sabotar seus recursos estratégicos.
} 


\section{Conclusão}

Mostramos, a partir do estudo de suas redes, tendo como fonte principal as correspondências, que essa liderança era muito maior do que até então acreditava-se, ela abrangia um espaço para além das fronteiras nacionais.

As renovações historiográficas ocorridas a partir da década de 1980, as biografias, também ganharam uma nova abordagem a partir destas, resignificando a compreensão da atuação dos indivíduos e suas narrativas dentro do processo histórico.

Nesse sentido, trabalhar com as correspondências do General Joca Tavares, apresentar a amplitude e a complexidade que envolvem os bastidores das tomadas de decisões, as articulações políticas, as dificuldades que enfrentavam, permite estabelecer um novo olhar sobre a Revolução Federalista de 1893-1895, em consonância com as preocupações da História Política renovada e suas metodologias que envolvem a utilização de biografias.

Tal abordagem permite entender a sociedade do período e a atuação de personagens políticos pertencentes a uma elite fronteiriça com características muito próprias, as quais possuíam seus próprios projetos de poder, nem sempre condizentes com os projetos do governo central. Procuramos demonstrar que sua atuação enquanto um político que tinha redes de relações sociais desde o Rio de Janeiro e que, ao mesmo tempo transfronteiriço, ultrapassava os limites políticos nacionais, abrangendo um espaço Platino. E o quanto estas foram relevantes para a entender parte de um processo político que teve repercussões na política nacional e no processo de consolidação da República no Sul do Brasil.

Dessa forma, procuramos apresentar a atuação de Joca Tavares enquanto mediador e negociador, especialmente no que diz respeito às relações com as outras lideranças federalistas, tanto militares quanto políticas. Esta proporcionou pensar a construção do político, do prestígio com que contava, o qual, como foi possível observar, teve por palco inicial o período imperial no Brasil e veio a ser amplamente utilizado para concatenar esforços em torno de seus objetivos pessoais e do grupo social que representava em meio a um contexto de conturbada transição política pelo qual passava o Brasil e também o Rio Grande do Sul.

Por fim, é possível compreender que sua atuação enquanto militar era, de acordo com o que evidenciamos, apenas uma dentre as diversas identidades que o sujeito pode 
assumir ao longo de sua vida, em que o político perpassa todos os momentos: nas negociações, nas mediações, nas estratégias engendradas pelos sujeitos, dentro do ambiente familiar, em diversos outros aspectos que vinham sendo, de certa forma, desconsiderados nas biografias tradicionais escritas sobre sua vida.

\section{Referências}

ANDRADE, Gustavo Figueira. A trajetória política do General João Nunes da Silva Tavares (Joca Tavares): família, comunicação e fronteira. Dissertação (Mestrado História). Santa Maria: Programa de Pós-Graduação em História, UFSM, 2017.

ARRIOLA, A. T. Propuesta de definición histórica para región. Estúdios de Historia Moderna y Contemporânea de México, Ciudad de México, n. 35, p. 181-204, jan./jun. 2008. Disponível em: < http://www.scielo.org.mx/pdf/ehmcm/n35/n35a6.pdf $>$. Acesso em: 26 nov. 2016.

AYROLO, V.; MÍGUEZ, E. Reconstruction of the Socio-Political Order after Independence in Latin America. A Reconsideration of Caudillo Politics in the River Plate. Jahrbuch für Geschichte Lateinamerikas - Anuário de História de América Latina, v. 49, n. 1, p. 1-16, dec. 2012.

AZÚA, C. R. de. Legitimidad, apoyo y poder político: ensaio de tipologia. Montevideo: Fundación de Cultura Universitaria, 1969.

BISCHOFF, A. W.; TAVARES, João Nunes da Silva. In: TAVARES, J. N. da S. Diário da Revolução Federalista de 1893. CABEDA, C. B. P.; AXT, G.; SEELING, R. V. (Org). Porto Alegre: Procuradoria Geral de Justiça, Projeto Memória, 2004. Tomo II. (Memória Política e Jurídica do Rio Grande do Sul, 3).

BOURDIEU, Pierre. A ilusão biográfica. In: FERREIRA, Marieta; AMADO, Janaína (org.). Usos e Abusos da História Oral. Rio de Janeiro: Editora FGV, 2006, p.183191.

CARVALHO, J. M. de. A construção da ordem: a elite política imperial e o teatro das sombras: a política Imperial. Rio de Janeiro: Civilização Brasileira, 2003.

CARVALHO, M. T. Nobiliário sul-riograndense. 2. ed. Porto Alegre: EDIGAL, 2011.

COSTA, Marcus Vinicius. A Revolução Federalista de (1893-1895): o contexto platino, as redes, os discursos e os projetos políticos Liberal-Federalistas. Dissertação (Mestrado em Integração Latino-Americana) - Universidade Federal de Santa Maria, Santa Maria, 2006.

DOBKE, P. R. Caudilhismo, território e relações sociais de poder: o caso de Aparício Saraiva na região fronteiriça entre Brasil e Uruguai (1896-1904). 2015. 132 p. Dissertação (Mestrado em História)-Universidade Federal de Santa Maria, Santa Maria, 2015. 
DONGHI, T. H. El Surgimiento de los caudillos en el cuadro de la sociedade rioplatense posrevolucionaria. Estúdios de Historia Social, ano 1, n. 1, Facultad de Filosofía y Letras, p. 121-149, oct. 1965.

FALLETI, T. G.; SISLIAN, F. Dominación Política: Redes Familiares y Clientelismo. Buenos Aires: Grupo Editor Universitário, 1996.

FARINATTI, L. A. E. Confins Meridionais: famílias de elite e sociedade agrária na fronteira meridional do Brasil. Santa Maria: Ed. da UFSM, 2010.

FARINATTI, Luis Augusto. Confins Meridionais: famílias de elite e sociedade agrária na fronteira sul do Brasil (1825-1865). Tese de Doutorado em História. Rio de Janeiro: PPG em História Social do IFCS-UFRJ, 2007. Apud VARGAS, J.M. Pelas margens do Atlântico: um estudo sobre elites locais e regionais no Brasil a partir das famílias proprietárias de charqueadas em Pelotas, Rio Grande do Sul (século XIX). Tese de Doutorado em História -Universidade Federal do Rio de Janeiro, Rio de Janeiro, 2013.

FÉRTIG, André. Clientelismo político em tempos belicosos: a Guarda Nacional da Província no Rio Grande do Sul na defesa do Império do Brasil (1850-1873). Santa Maria: Editora da UFSM, 2010.

FLORES, M.; FLORES, H. A. H. Rio Grande do Sul: aspectos da Revolução de 1893. Porto Alegre: Martins Livreiro, 1999.

FLORES, Moacyr (org.) 1893-95: a Revolução dos maragatos. Porto Alegre: EDIPUCRS, 1993.

FRANCO, S. da C. A Guerra Civil de 1893. 2. ed. ampl. Porto Alegre: Edigal, 2012.

FRANCO, S. da C. Júlio de Castilhos e sua época. Porto Alegre: UFRGS, 1996.

GOMES, Â. de C. (org.). Capanema: o ministro e seu ministério. Rio de Janeiro: Editora FGV, 2000.

GOMES, Â. de C. (org.). Escrita de si, escrita da História. Rio de Janeiro: FGV, 2004.

GRAHAM, R. Clientelismo e política no Brasil do século XIX. Tradução de Celina Brandt. Rio de Janeiro: Editora UFRJ, 1997.

LEVILLAIN, P. Os protagonistas: da biografia. In: RÉMOND, R. Por uma história Política. Tradução de Dora Rocha. 2. ed. Rio de Janeiro: Editora FGV, 2003.

LOPES, F. H. Fontes Históricas: desafios, propostas e debates. Revista História da Historiografia, Ouro Preto, n. 10, p. 315-322, dez. 2012.

MORITZ, G. Acontecimentos políticos do Rio Grande do Sul: parte I e II. Organização de Gunter Axt et al. Porto Alegre: Procuradoria-Geral da Justiça, Projeto Memória, 2005.

OLIVEIRA, L. R. Nas veredas do Império: guerra, política e mobilidades através da trajetória do Visconde de Serro Alegre (Rio Grande do Sul, c.1790 - c.1870). 2016. 
Dissertação (Mestrado em História)-Pontifícia Universidade Católica do Rio Grande do Sul, Porto Alegre, 2016.

PADOIN, M. M. O federalismo no espaço fronteiriço platino. 1999. Tese (Doutorado em História) -Universidade Federal do Rio Grande do Sul, Porto Alegre, RS, 1999.

PADOIN, Maria Medianeira; ROSSATO, Monica (org.). Gaspar Silveira Martins: perfil biográfico, discursos e atuação na Assembleia Provincial. Porto Alegre:

Assembleia Legislativa do Rio Grande do Sul, 2013. (Série Perfis Parlamentares; 13.)

PORTO ALEGRE, A. Homens Ilustres do Rio Grande do Sul. Porto Alegre: Selbach, 1917.

RECKZIEGEL, A. L. S. A diplomacia marginal: vinculações políticas entre o Rio Grande do Sul e o Uruguai (1893-1904). Passo Fundo: UPF, 1999.

REIS, J. Apontamentos Históricos e Estatísticos de Bagé. Bagé: Tipografia do Jornal Correio do Povo, 1911.

ROSSATO, M. Relações de poder na região fronteiriça platina: família, trajetória e atuação política de Gaspar Silveira Martins. 2014. 163 p. Dissertação (Mestrado em História) -Universidade Federal de Santa Maria, Santa Maria, 2014.

SAFFORD, F. Política, Ideologia y Sociedad. In: BETHEL, L. (coord.). Historia de América Latina: América latina independiente, 1820-1870. v. 6, p. 42-104, 1991.

TAVARES, F. da S. Diário da Revolução Federalista de 1893. In: CABEDA, C. B. P.; AXT, G.; SEELING, R. V. (org). Porto Alegre: Procuradoria Geral de Justiça, Projeto Memória, 2004. Tomo I. (Memória Política e Jurídica do Rio Grande do Sul, 3).

VARGAS, J. M. Entre a Paróquia e a Corte: uma análise da elite política do Rio Grande do Sul (1868 - 1889). 2007. Dissertação (Mestrado em História)-Universidade Federal do Rio Grande do Sul, Porto Alegre, 2007.

VARGAS, J. M. Pelas margens do Atlântico: um estudo sobre elites locais e regionais no Brasil a partir das famílias proprietárias de charqueadas em Pelotas, Rio Grande do Sul (século XIX). Tese (Doutorado em História)-Universidade Federal do Rio de Janeiro, Rio de Janeiro, 2013.

\section{DOCUMENTAIS}

\section{Acervo de correspondências do General Joca Tavares}

ACERVO Particular da Família Tavares, Cidade de Bagé, RS. Transcrição realizada por Gustavo Figueira Andrade.

SANTOS, M. [Carta] 16 nov. 1885, Montevidéu. [para] TAVARES, João Nunes da Silva. Bagé, 1 folha. Pede para que o General Tavares envie seus cumprimentos a seu amigo em comum Coronel Muniz quando o visitar. Acervo Particular da senhora Yara Maria Botelho Vieira, Bagé, RS. Transcrição de Gustavo F. Andrade, 2019. 
PEIXOTO, F. V. [Telegrama] 4 abr. 1892, Rio de Janeiro. [para] TAVARES, João Nunes da Silva. Bagé, 1 folha. Procurando resolver a grave situação em que se encontrava o estado do Rio Grande do Sul. Acervo Particular da senhora Yara Maria Botelho Vieira, Bagé, RS. Transcrição de Gustavo F. Andrade, 2019.

PELOTAS, Visconde. [Telegrama] 14 jun. 1892, Porto Alegre. [para] TAVARES, João Nunes da Silva. Bagé, 3 folhas. Prevê turbulências na política do Rio Grande do Sul devido ação do Partido Republicano Rio-grandense fala em inevitabilidade do conflito, declara que precisaria de um homem que pudesse fazer frente a um levantamento Castilhista. Acervo Particular da senhora Yara Maria Botelho Vieira, Bagé, RS. Transcrição de Gustavo F. Andrade, 2019. 